\title{
Effect of Geometric Parameters and Moisture Content on the Mechanical Performances of 3D-Printed Isogrid Structures in Short Carbon Fiber-Reinforced Polyamide
}

\author{
Valerio Di Pompeo, Archimede Forcellese, Tommaso Mancia, Michela Simoncini (D), and Alessio Vita
}

\author{
Submitted: 18 December 2020 / Revised: 19 February 2021 / Accepted: 6 March 2021 / Published online: 29 March 2021
}

\begin{abstract}
The present paper aims at studying the effect of geometric parameters and moisture content on the mechanical performances of 3D-printed isogrid structures in short carbon fiber-reinforced polyamide (namely Carbon PA). Four different geometric isogrid configurations were manufactured, both in the undried and dried condition. The dried isogrid structures were obtained by removing the moisture from the samples through a heating at $120^{\circ} \mathrm{C}$ for $4 \mathrm{~h}$. To measure the quantity of removed moisture, samples were weighted before and after the drying process. Tensile tests on standard specimens and buckling tests on isogrid panels were performed. Undried samples were tested immediately after 3D printing. It was observed that the dried samples are characterized by both Young modulus and ultimate tensile strength values higher than those provided by the undried samples. Similar results were obtained by the compression tests since, for a given geometric isogrid configuration, an increase in the maximum load of the dried structure was detected as compared to the undried one. Such discrepancy tends to increase as the structure with the lowest thickness value investigated is considered. Finally, scanning electron microscopy was carried out in order to analyze the fractured samples and to obtain high magnification three-dimensional topography of fractured surfaces after testing.
\end{abstract}

Keywords 3D printing, buckling, carbon fiber composites, CFRP, isogrid

\section{Introduction}

Additive manufacturing is an emerging technology which is revolutionizing the word of manufacturing. The possibility of realizing complex shapes, rapidly producing components, avoiding molds and automating processes makes this technique very attractive for several manufacturing sectors (Ref 1-3). Different 3D printing techniques were developed to additively manufacture plastics, metals and other materials (Ref 4). As far as the plastic materials are concerned, the fused filament fabrication (FFF) is the most used technology due to its reliability and relative low cost. FFF is an extrusion process performed by heating a continuous thermoplastic filament and

Supplementary Information The online version contains supplementary material available at https://doi.org/10.1007/s11665-02 1-05659-7.

This invited article is part of a special topical focus in the Journal of Materials Engineering and Performance on Additive Manufacturing. The issue was organized by Dr. William Frazier, Pilgrim Consulting, LLC; Mr. Rick Russell, NASA; Dr. Yan Lu, NIST; Dr. Brandon D. Ribic, America Makes; and Caroline Vail, NSWC Carderock.

ValerioDiPompeo, Archimede Forcellese, Tommaso Mancia, and Alessio Vita, DIISM, Università Politecnica delle Marche, Ancona, Italy; and Michela Simoncini, Università degli Studi eCampus, Novedrate, CO, Italy. Contact e-mails: m.simoncini@staff.univpm.it and michela.simoncini@uniecampus.it. exploiting a layer by layer deposition over a plate (Ref 5,6$)$. In order to improve the mechanical properties of FFF 3D-printed plastic components, short carbon fibers can be added as reinforcement of the thermoplastic material (Ref 7, 8). Carbon fiber-reinforced polyamide (CFRP) parts can be produced by 3D printing, especially as easy processing thermoplastic materials are used (Ref 9). Ning et al. investigated the effect of content and length of short carbon fibers added into ABS plastic on the mechanical properties of FFF fabricated part and demonstrated that adding carbon fiber into plastic materials can increase tensile strength and Young's modulus, but can decrease toughness, yield strength, and ductility (Ref 10). Polyamides (PA) can also be reinforced with different types of nanofillers, including glass fibers and microspheres (Ref 11), but also with adding short carbon fibers (Ref 12, 13). In previous papers, the authors demonstrated that FFF technology can be successfully used to realize composite isogrid structures, that are of interest in the aerospace field (Ref 14, 15). As a matter of fact, isogrid are lattice structures realized by means of triangular stiffening ribs, in order to ensure high specific compression resistance to thin structures such as fuselage panels, fuel tanks, boosters, etc. (Ref 16, 17). Forcellese et al. demonstrated that the geometric parameters of the elementary lattice cell and the structure, such as the rib thickness, rib width and cell height, have to be accurately chosen since they strongly influence the mechanical performances of the 3Dprinted isogrid (Ref 14, 15). Specifically, according to the results shown by Wang and Abdalla (Ref 18) and by Elumalai et al. (Ref 19), the authors demonstrated that buckling, that is the typical failure mode of compressive-loaded isogrid structures, can occur in two different modes: global and local buckling. The global buckling occurs when the whole isogrid structure collapses (Ref 20), while the local one involves the localized failure of the ribs (Ref 21). Unfortunately, PA presents 
high hygroscopic capacity which can cause a moisture adsorption during 3D printing process, resulting in a decrease of mechanical properties of additively manufactured components (Ref 11). No studies can be found concerning the effect of moisture adsorbed by the polyamide material on the mechanical performances of isogrid panels.

In this framework, the present investigation aims at analyzing the effect of geometric parameters and moisture content on the mechanical performances of 3D-printed isogrid structures in Carbon PA. To this purpose, four different geometric configurations of isogrid panels were manufactured, both in the undried and the dried condition. Specifically, the dried isogrid structures were obtained by removing the moisture from the samples through a heating at $120{ }^{\circ} \mathrm{C}$ for $4 \mathrm{~h}$. To measure the quantity of removed moisture, samples were weighted before and after the drying process. Tensile tests on standard specimens and buckling tests on isogrid panels were performed. Undried samples were tested immediately after 3D printing. Finally, the fractured samples were analyzed by means of scanning electron microscopy and high magnification three-dimensional topography of fractured surfaces after testing were obtained.

\section{Fabrication and Testing}

\subsection{Material and Printing Process}

The composite material used in this study, defined as Carbon PA, consists of a polyamide 6 reinforced with short carbon fibers at $20 \%$ in weight, whose length and diameter are equal to about $2000 \mu \mathrm{m}$ and $7 \mu \mathrm{m}$, respectively (aspect ratio, that is the ratio between length and diameter, of about 280).

According to the material datasheet, Carbon PA is characterized by a density equal to $1.43 \mathrm{~g} / \mathrm{cm}^{3}$, an elastic modulus of $15.5 \mathrm{GPa}$ and ultimate tensile strength equal to $138 \mathrm{MPa}$, as also shown by authors in (Ref 14). The chosen material is supplied by Roboze S.P.A. in the form of a $1.75 \mathrm{~mm}$ diameter filament, suitable for processing through the fused filament fabrication technique (FFF). For the additive manufacturing process, the Roboze One +400 3D printer, equipped with FFF technology and supplied by Roboze Spa, was used with the aim of realizing the isogrid structures to be used for improving compression resistance to flat components for automotive or aerospace applications. Since the material is strongly subjected to moisture absorption, which causes a significant decrease in mechanical properties, Carbon PA was subjected to a drying process for about $4 \mathrm{~h}$ at the temperature of $120{ }^{\circ} \mathrm{C}$ before the printing process. Moreover, during the printing phase, the material was maintained at $70{ }^{\circ} \mathrm{C}$ in a controlled environment to avoid moisture adsorption and to improve printing quality, reducing void formation. Carbon PA filament extrusion was performed at a temperature of $240{ }^{\circ} \mathrm{C}$, higher than the glass transition temperature of polyamide, using a nozzle of $0.6 \mathrm{~mm}$ in diameter. For this $3 \mathrm{D}$ printer, it is not expected a temperature-controlled chamber, but only the building plate temperature can be modified. In this case, the plate temperature has been set to $45^{\circ} \mathrm{C}$, in order to avoid detachment of the sample.

\subsection{Design Parameters of Isogrid Structures}

The isogrid structures were designed by means of a CAD software, by choosing the rib width and rib thickness in the ranges of 3-5 $\mathrm{mm}$ and $4-15 \mathrm{~mm}$ respectively, as reported in
Table 1. As far as the other geometric parameters are concerned, for all isogrid structures, the same values of cell height, global length and global width, equal to 18, 106 and $80 \mathrm{~mm}$, respectively, were chosen. The construction parameters mentioned before are shown in Fig. 1(a).

The CAD files were then exported as an STL file and imported into slicing software that translates $3 \mathrm{D}$ model into instructions for the 3D printer by creating a GCODE file. The software allowed to set the printing parameters: in this research, an infill density equal to $100 \%$, infill angle offset of $60^{\circ}$ and average printing speed of $50 \mathrm{~mm} / \mathrm{s}$ print were chosen. A total of 16 isogrid structures in 8 different configurations were realized. After 2 weeks since printing, isogrid was subjected to another drying process in the oven for $4 \mathrm{~h}$ at $120{ }^{\circ} \mathrm{C}$ to remove the moisture absorbed during and after printing. In order to quantify the moisture removed, isogrid structures were weighted before and after the second drying process using an analytical balance with a resolution of $0.1 \mathrm{mg}$.

\subsection{Tensile Test}

In order to characterize the mechanical behavior of polyamide reinforced with short carbon fibers, tensile tests were carried out according to the ASTM D3039 standard. To this purpose, dog bone samples were additively printed using the Roboze One +400 at the maximum infill, choosing as extrusion direction the tensile loading one (Ref 22). The tensile sample was characterized by a gauge length, width and thickness equal to 80,10 and $2 \mathrm{~mm}$, respectively. End tabs were realized in order to bear the concentrate clamping load. In order to investigate the effect of moisture content on the mechanical performances of carbon fiber-reinforced polyamide, samples were heated in an oven at $120^{\circ} \mathrm{C}$ for $4 \mathrm{~h}$ and then tested at room temperature using the universal testing machine MTS 810. During tensile tests, the load $(P)$ and nominal strain (e) along the loading direction were acquired using a load cell and an extensometer; the ratio between load and initial area of cross section allowed to evaluate the nominal stress $(s)$ value. To guarantee the repeatability of the results, three tensile tests were performed on the CFRP samples. The results obtained by tensile tests on 3D-printed samples were compared to the mechanical behavior of single filament before $3 \mathrm{D}$ printing procedure.

\subsection{Buckling Test of Isogrid Structures}

Buckling tests of isogrid panels were carried out on the servo-hydraulic testing machine MTS 810 in a displacement control equal to $0.5 \mathrm{~mm} / \mathrm{min}$ (Fig. 1b). In order to feature the bending effect on isogrid structures in Carbon PA, lattice structures were arranged with the shortest side in contact with the plate. To determine the load $(P)$ and the displacement $(\Delta h)$ during testing, the data were acquired with a load cell and a linear variable displacement transducer (LVDT), respectively. The buckling tests were carried out three times for each geometric configuration investigated, thus allowing results

Table 1. Dimensions of the tested isogrid structures

\begin{tabular}{lllllllll}
\hline Rib width, mm & $\mathbf{3}$ & $\mathbf{3}$ & $\mathbf{3}$ & $\mathbf{3}$ & $\mathbf{5}$ & $\mathbf{5}$ & $\mathbf{5}$ & $\mathbf{5}$ \\
\hline Rib thickness, mm & 4 & 8 & 10 & 15 & 3 & 8 & 10 & 15 \\
\hline
\end{tabular}




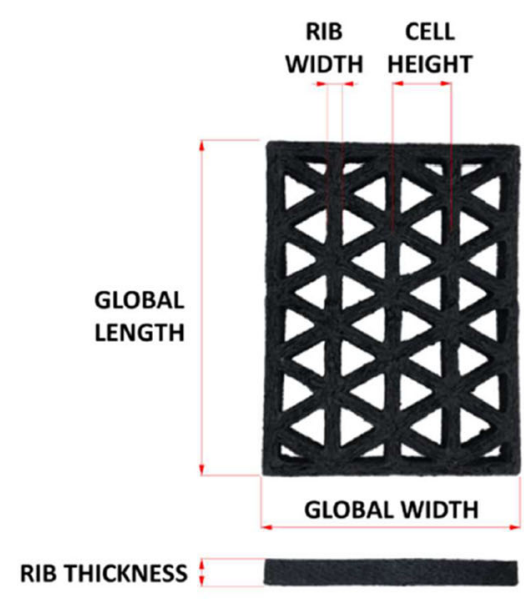

(a)

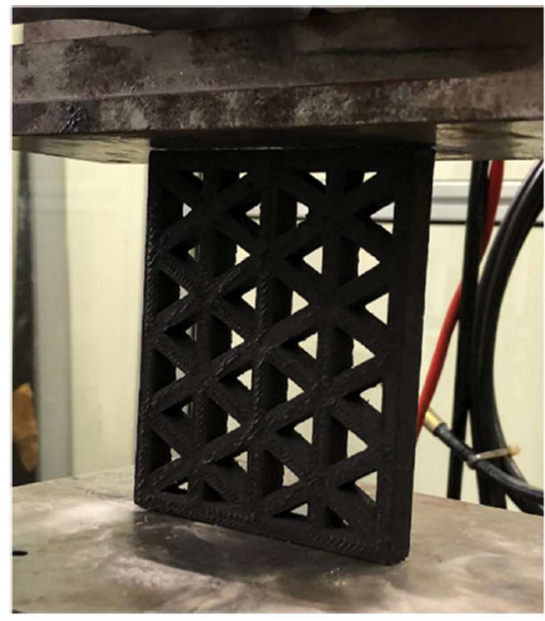

(b)

Fig. 1. (a) Geometrical parameters of an isogrid structure and (b) buckling tests of isogrid structure

consolidation. Moreover, test images were acquired, using a dedicated camera, to highlight the different failure mode of dried and undried isogrid structures. The maximum specific buckling load (Pmax/w) was derived by the results of buckling tests, calculating the ratio between the maximum buckling load Pmax and the weight of the structure before testing.

\subsection{Scanning Electron Microscope Analysis}

The cross section of filament in Carbon PA, before and after $3 \mathrm{D}$ printing process, was analyzed using the scanning electron microscope FESEM ZEISS SUPRATM 40, with compact GEMINI ${ }^{\circledR}$ objective lens, in order to acquire high magnification three-dimensional topography of the Carbon PA to be printed and to evaluate the effect of FFF technique on the short carbon fiber orientation. Furthermore, fractured surfaces of deformed isogrid structures subjected to buckling tests were analyzed using SEM analysis in order to obtain high magnification topography of fractured surfaces of deformed isogrid structures. The samples for SEM investigation were coated by means of a metallization process in order to make it conductive for the analysis. The 3D-printed filaments were embedded and polished for scanning electron microscope analysis.

\section{Results and Discussion}

\subsection{Tensile Test}

A typical stress versus strain curve of the 3D-printed CFRP dried sample is plotted in Fig. 2. As it can be seen, the curve is linear at low deformation values, with high elastic modulus $(E)$ which tends to decrease as the deformation increases, reflecting the typical behavior of filled plastics. According to the ASTM D3039, E was calculated at strain values ranging between 0.001 and 0.003 ; the mean elastic modulus value of $14.1 \pm 0.4 \mathrm{GPa}$ was obtained by three tested samples. As far as the ultimate tensile strength (UTS) is concerned, the mean value obtained was equal to $138 \pm 6 \mathrm{MPa}$. The good repeatability of the results is demonstrated by the low standard deviations calculated. The results of E and UTS for the undried tensile samples were $13.5 \mathrm{GPa}$ and $127 \mathrm{MPa}$, respectively, as shown by the authors in (Ref 14). By comparing the results obtained by the undried and dried samples (Fig. 2), an increase both in the Young's modulus of $4 \%$ and in the ultimate tensile strength of $9 \%$ was obtained by removing the moisture adsorbed by the polyamide through the drying process.

These results are fully in line with those present in literature (Ref 23,24$)$, thus demonstrating that also in the 3D printing process, the presence of humidity tends to degrade the interfacial stress transfer efficiency between fibers and polyamide.

In addition, results of the tensile test performed on Carbon PA filaments are reported in Fig. 3. As it can be observed, the maximum stress is similar to that of 3D-printed tensile specimens while the maximum strain is sensibly higher. This behavior is in agreement with that reported in scientific literature $(\operatorname{Ref} 25,26)$.

\subsection{Buckling Test of Isogrid Structures}

Compression tests performed on isogrid structures showed that both dried and undried samples fail under buckling. Figure 4(a) shows typical load vs. displacement curves recorded during buckling tests on dried and undried isogrid structures, characterized by the same geometrical parameters. Irrespective of the moisture content, it can be seen that the load increases with displacement up to a peak value $(P \max )$ reached at to the onset of buckling of structure (global buckling) or ribs (local buckling).

More in detail, global buckling, which causes the collapse of the whole structure, occurs in isogrid structures characterized by small rib thicknesses, while local buckling, leading to a localized failure of ribs, appears as the rib thickness increases (Ref 18). Figure 4(a) also shows that, for a given displacement, the dried configuration is characterized by a rise in the load applied to the isogrid structure during buckling test. The effect of moisture content on the fracture mechanisms of structures can be observed in the different ways in which structures collapse. As it can be seen by the videos attached at the present work as supplementary materials, the thicker undried structures investigated in the present paper, characterized by a rib thickness of $15 \mathrm{~mm}$, failed under local buckling (video 1), differently from thinner structures (rib thickness equal to 4,8 


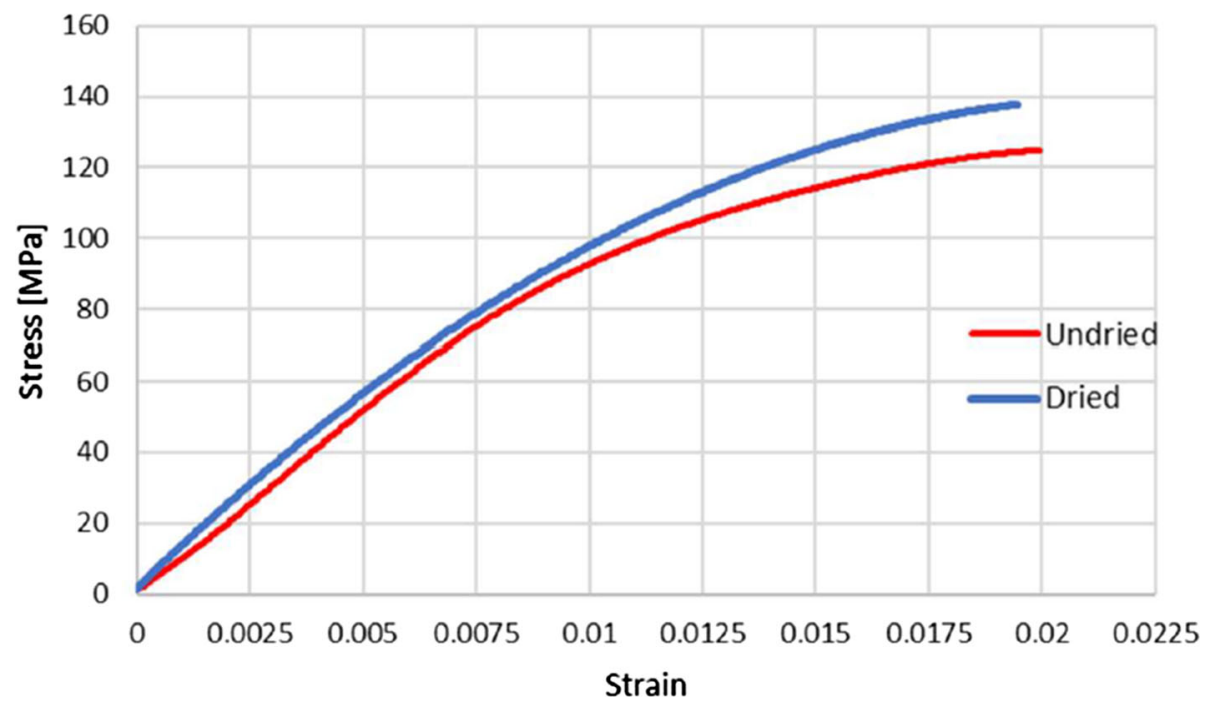

Fig. 2. Typical stress vs. strain curves of 3D-printed CFRP dried and undried samples

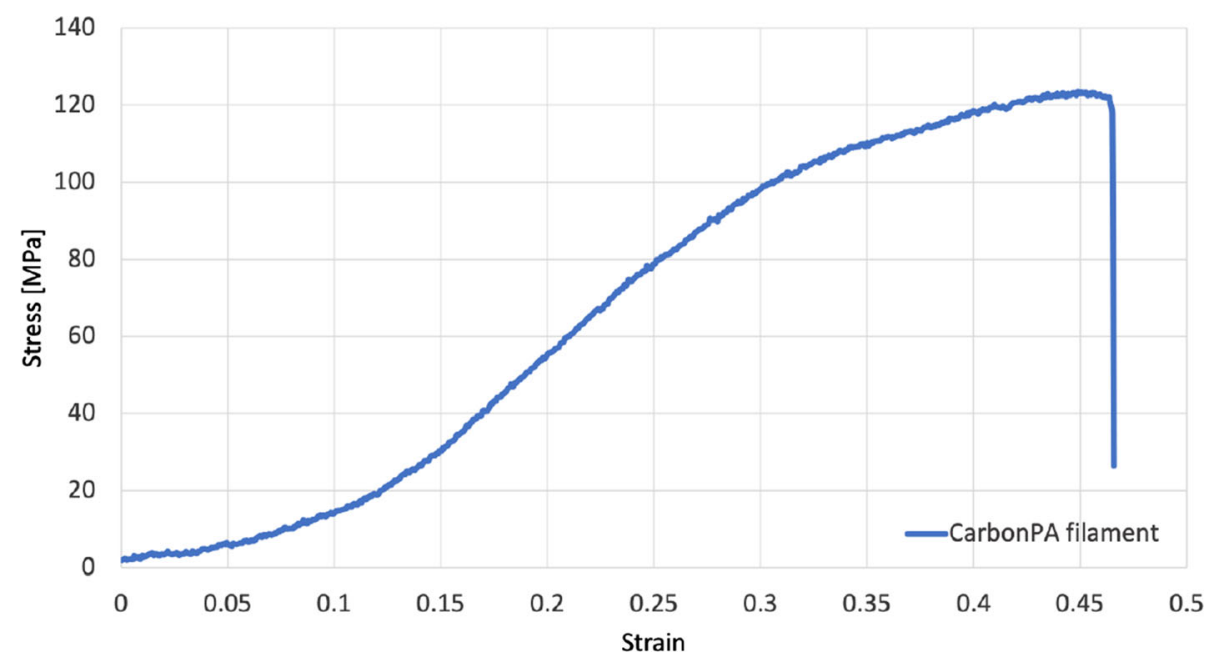

Fig. 3. Typical stress vs. strain curve of Carbon PA filament
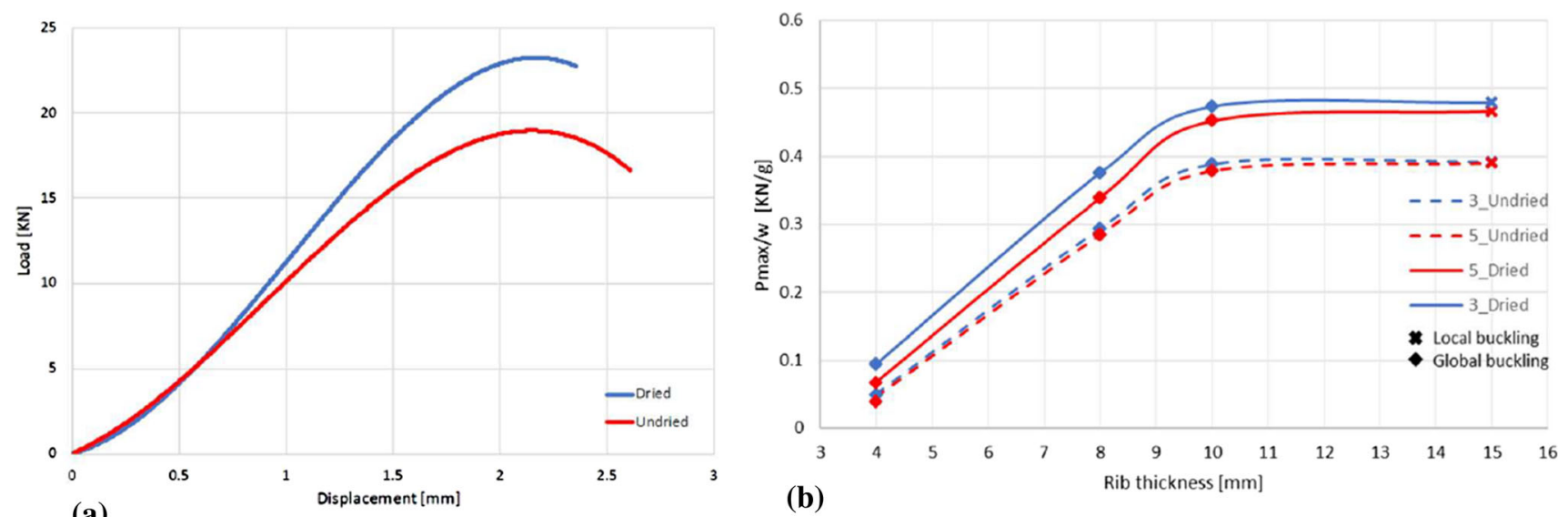

(a)

(b)

Fig. 4. (a) Effect on the moisture content on the typical load vs. displacement curves of an isogrid structure in polyamide resin reinforced with short carbon fibers (rib width $=5 \mathrm{~mm}$, rib thickness $=8 \mathrm{~mm}$ ), and (b) effect of rib width on the specific maximum load vs. rib thickness curves obtained by isogrid structures under buckling test 
and $10 \mathrm{~mm}$ ) which underwent to global buckling phenomena (video 2). However, the undried samples exhibited a ductile failure, characterized by a plastic deformation with activates internal micro failures. On the contrary, the dried configuration was characterized by a brittle failure, which causes an explosive rupture (video 3). Specifically, by observing the last frames of the video before the onset of fracture, it can be seen that the thicker dried structures deform under local buckling, while the thinner ones deform with a global buckling mode. Moreover, the moisture has no effect on the failure mode. Figure 5 shows the pre-failure frames of the acquired videos and the relative post-test isogrid structures.

Typical maximum specific buckling load $(P \max / \mathrm{w})$ versus rib thickness curves are shown in Fig. 4(b). Irrespective of the rib width investigated, it is worth to notice that $\mathrm{Pmax} / \mathrm{w}$ ratio
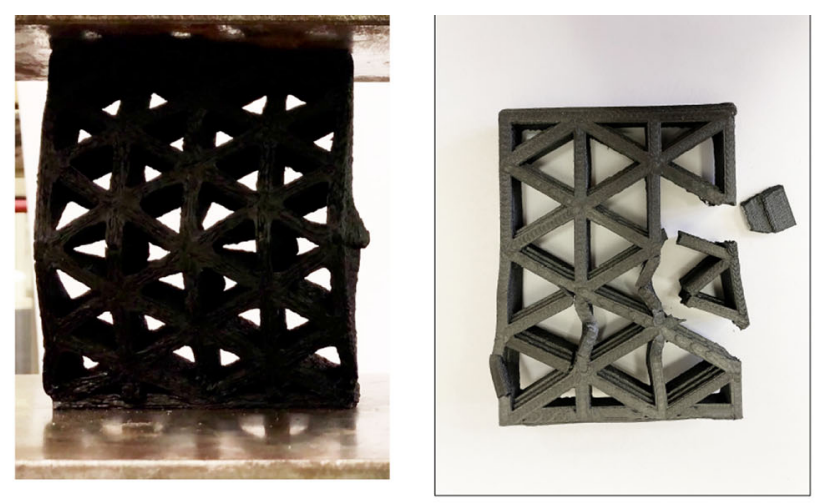

(a)
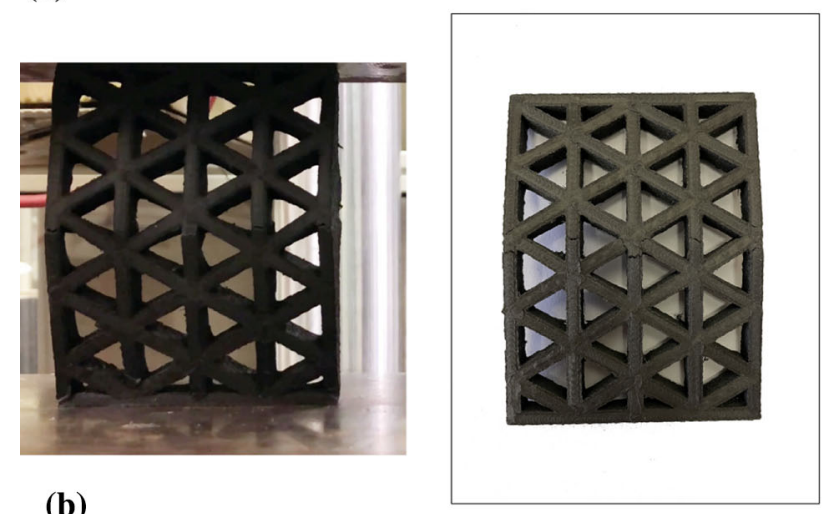

(b)
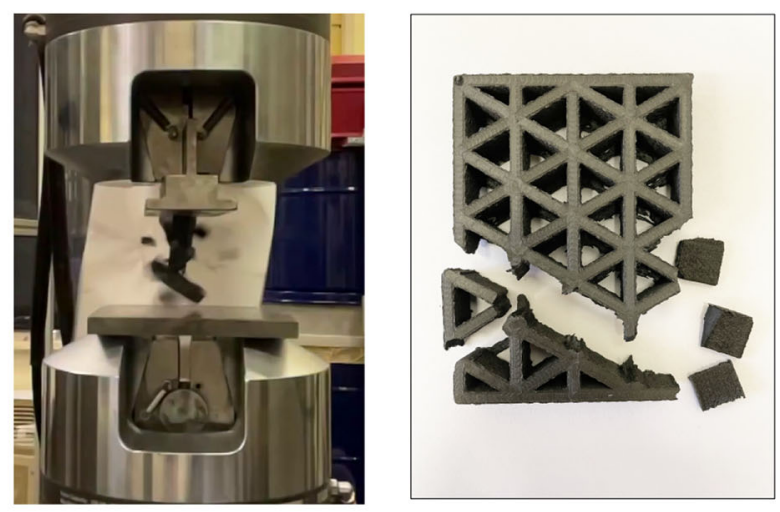

(c)

Fig. 5. Pre-failure video frame and relative isogrid structure of: (a) local buckling, (b) global buckling and (c) explosive failure enhances linearly with rib thickness until the value of rib thickness equal to $10 \mathrm{~mm}$ is reached. Then, as the rib thickness further increases up to $15 \mathrm{~mm}$, the growth rate of the $P \max / \mathrm{w}$ strongly decreases. This behavior can be attributed to the onset of local buckling which results in a lower load carrying capacity of structures, as demonstrated by Wang and Abdalla (Ref 18). Furthermore, the $P \max / \mathrm{w}$ values tend to decrease with increasing rib width. Such discrepancy is less marked as the undried configurations were considered.

Table 2 summarizes the $P \max$ and the Pmax/w for each tested structure, as well as the moisture loss during the drying process of the samples. It can be observed that the drying process allows to increase both resistance and specific resistance of the isogrid structures. In the last column, this increase in resistance was obtained by calculating the growth rate between the specific resistance of an undried isogrid structure and the correspondent in the dried configuration.

The increase in the specific resistance and the moisture loss is also plotted in Fig. 6 for a better understanding. It can be observed that the more the moisture is removed, the more the specific resistance increases. In addition, the structures with a thickness of $4 \mathrm{~mm}$ present the highest values of moisture loss (1.16 and $0.97 \%$ ) as well as the highest increase in specific resistance (47 and 32\%), denoting that moisture was easily removed from thin structures. As far as the isogrids with a rib thickness higher than $4 \mathrm{~mm}$ is concerned, the moisture loss ranges from 0.72 to $0.89 \%$ while the increase in resistance from 16 to $22 \%$. In addition, irrespective of the rib width, it can be noted that as the rib thickness decreases, the increase in resistance tends to enhance. Then, the increase in resistance is higher in structures with a rib width of $3 \mathrm{~mm}$ with respect the ones characterized by a rib width of $5 \mathrm{~mm}$.

\subsection{Scanning Electron Microscope Analysis}

SEM images of the filament before and after 3D printing technique are shown in Fig. 7. It can be observed that the original filament is characterized by a porosity spread over the entire cross section of the Carbon PA filament and the short carbon fibers are randomly arranged (Fig. 7a). On the contrary, the 3D-printed filament exhibits fibers aligned in the direction of extrusion; furthermore, the cross section no longer shows the initial porosity (Fig 7b).

SEM images of fractured surfaces of both undried and dried isogrid structures after buckling tests are shown in Fig. 8. By considering the dried configuration of isogrid (Fig. 8a and c), the fibers appear less enveloped in resin, probably due to the absence of moisture. As far as the fractured surface of undried isogrid is concerned (Fig. $8 \mathrm{~b}$ and d), it can be observed a surface characterized by a matrix yielding and matrix and fibers debonding, attributed to the presence of water molecules into the polyamide which causes ductile fracture of the matrix and physical damage of fiber-matrix interface.

\section{Conclusion}

In this paper, composite isogrid structures in polyamide reinforced with $20 \%$ in weight of short carbon fibers were produced by FFF $3 \mathrm{D}$ printing. The effect of geometric parameters and moisture content on buckling behavior of isogrid structures was investigated. The main results can be summarized as follows: 
Table 2. Pmax, Pmax/w, moisture loss and increase in specific resistance of the isogrid structures under buckling test

\begin{tabular}{|c|c|c|c|c|c|c|}
\hline \multirow[b]{2}{*}{ Structure } & \multicolumn{2}{|c|}{ Undried } & \multicolumn{2}{|c|}{ Dried } & \multirow{2}{*}{\multicolumn{2}{|c|}{ Moisture loss, \%Increase in specific resistance, $\%$}} \\
\hline & Pmax, KN & $P \max / w, K N / g$ & Pmax, KN & $\operatorname{Pmax} / w, K N / g$ & & \\
\hline $3 \times 4$ & 1.1 & 0.05 & 2.07 & 0.09 & 1.16 & $47 \%$ \\
\hline $3 \times 8$ & 13.2 & 0.29 & 14.85 & 0.38 & 0.89 & $22 \%$ \\
\hline $3 \times 10$ & 21.3 & 0.39 & 24.0 & 0.47 & 0.89 & $18 \%$ \\
\hline $3 \times 15$ & 32.1 & 0.39 & 35.4 & 0.48 & 0.87 & $18 \%$ \\
\hline $5 \times 4$ & 1.68 & 0.05 & 2.48 & 0.07 & 0.97 & $32 \%$ \\
\hline $5 \times 8$ & 19.37 & 0.28 & 23.56 & 0.34 & 0.74 & $16 \%$ \\
\hline $5 \times 10$ & 31.6 & 0.38 & 37 & 0.45 & 0.81 & $16 \%$ \\
\hline $5 \times 15$ & 49.73 & 0.39 & 59.25 & 0.47 & 0.72 & $16 \%$ \\
\hline
\end{tabular}

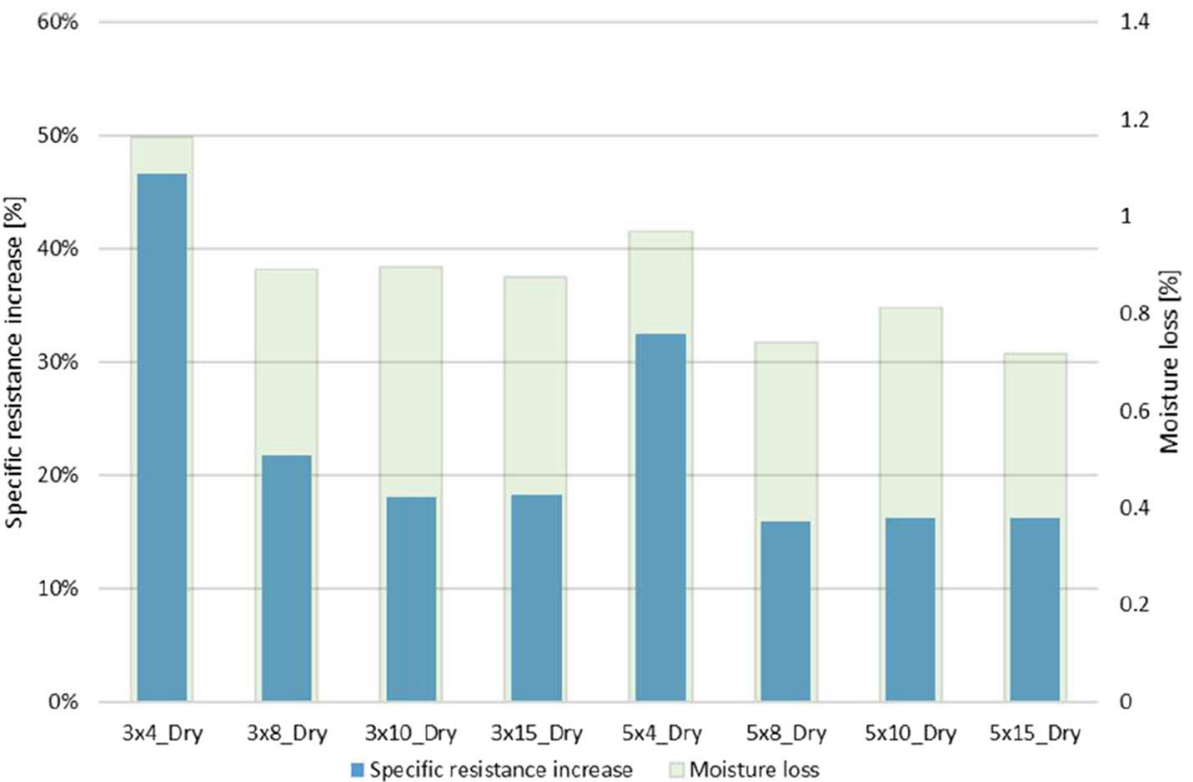

Fig. 6. Specific resistance and moisture loss of the CFRP isogrid structures

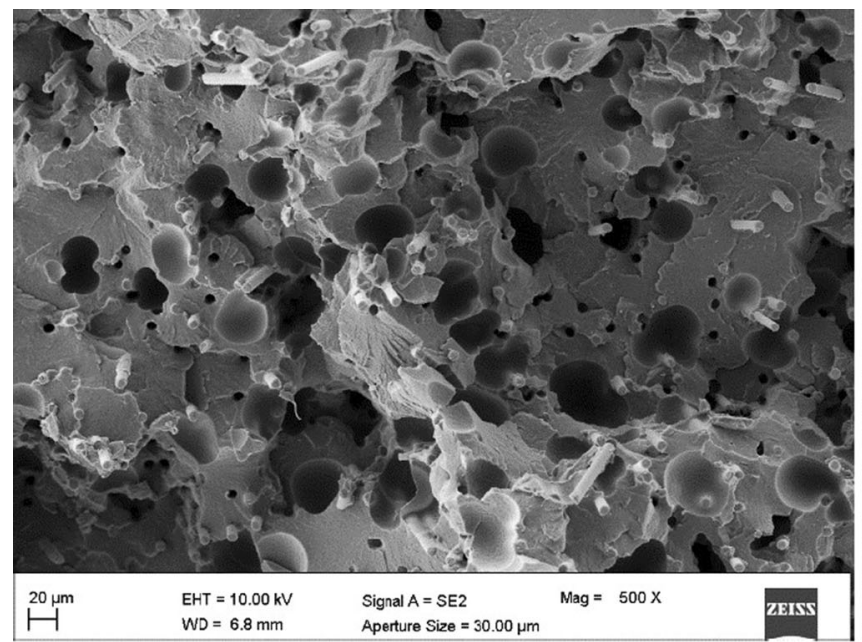

(a)

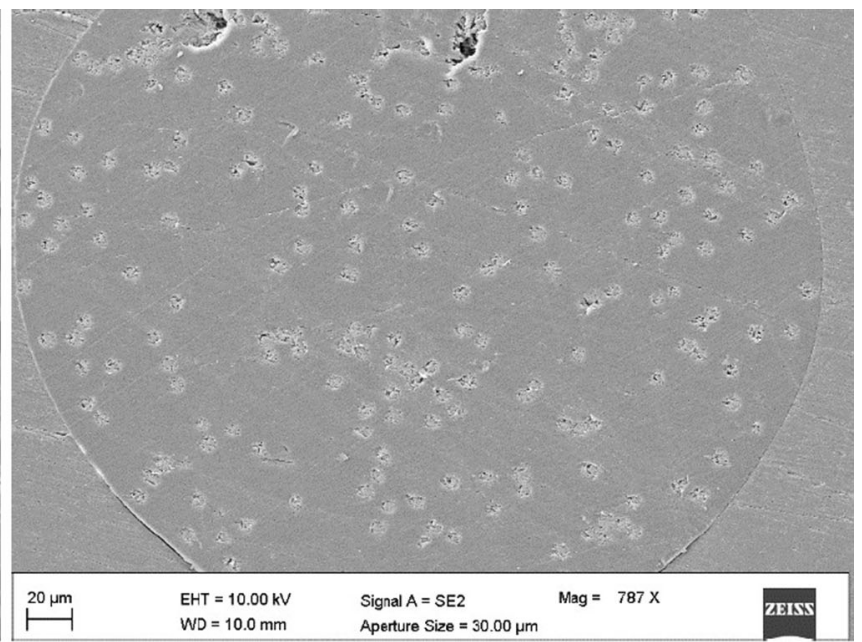

(b)

Fig. 7. SEM images of the Carbon PA filament cross section (a) before $3 \mathrm{D}$ printing and (b) after 3D printing 


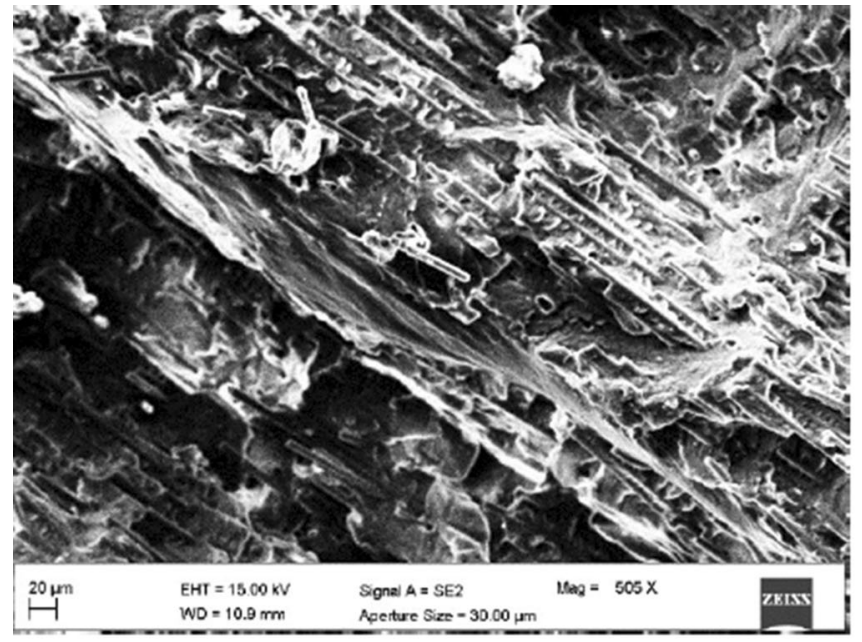

(a)

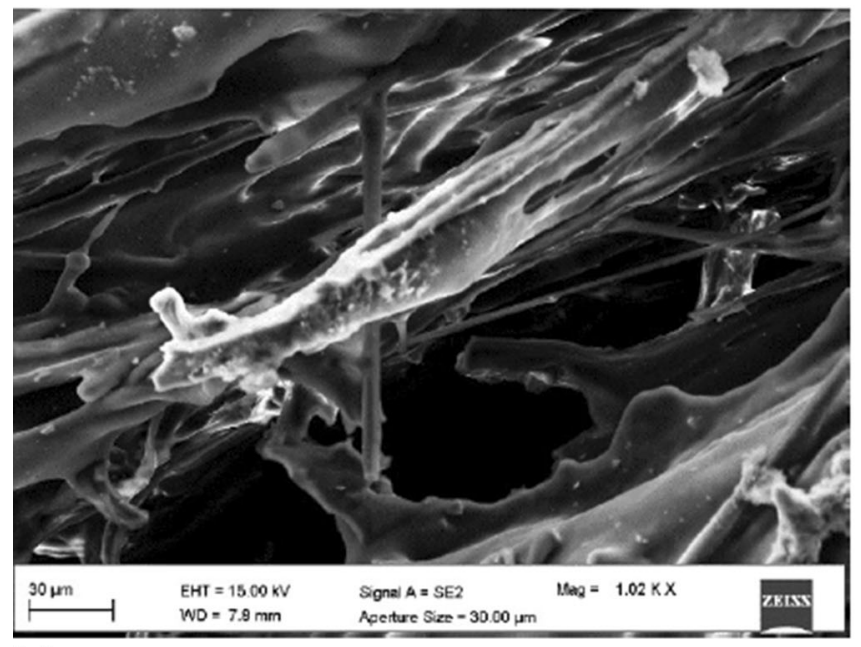

(c)

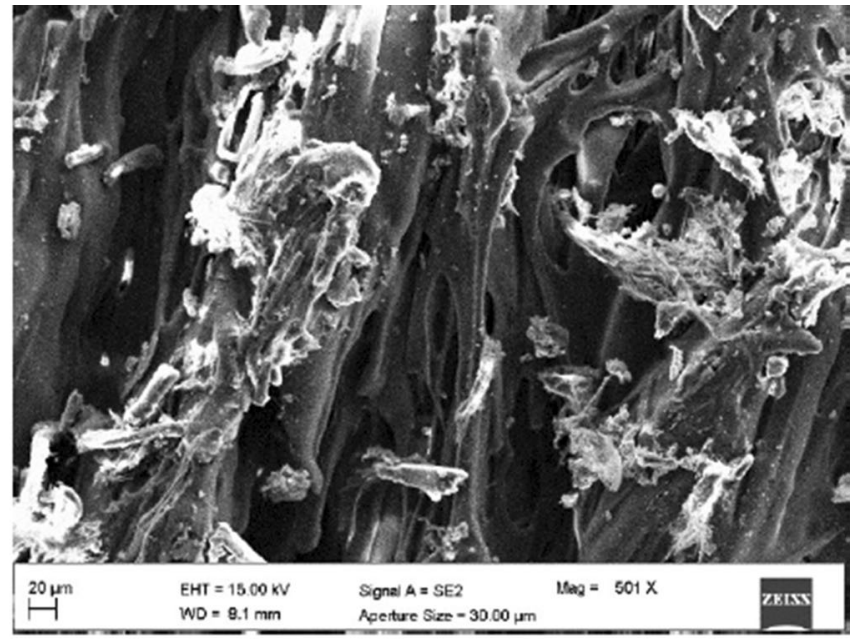

(b)

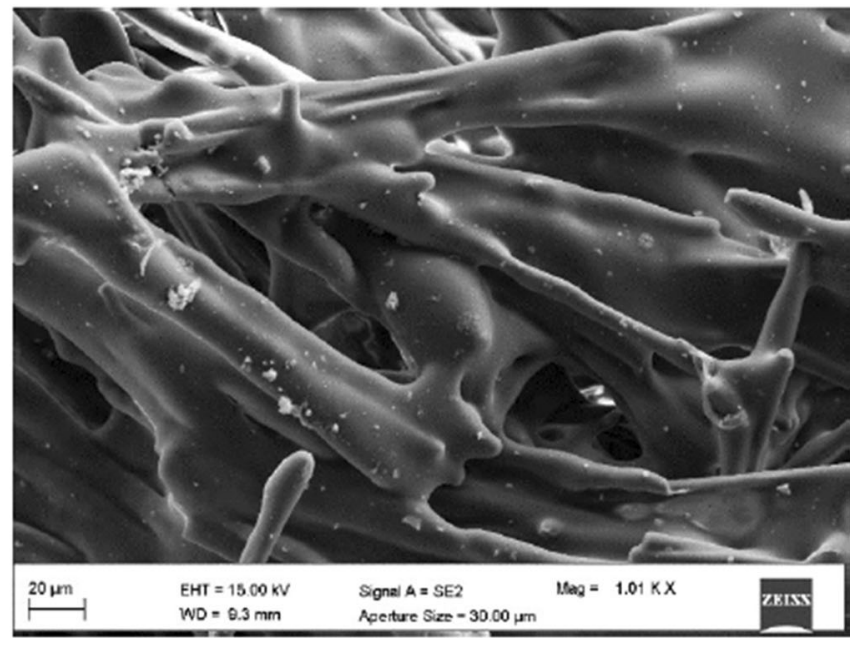

(d)

Fig. 8. SEM micrographs of fractured surfaces of: (a) and (c) dried isogrid structure; (b) and (d) undried isogrid structure

- The load recorded during buckling test increases with displacement up to a peak value reached at to the onset of buckling; the dried configuration is characterized by a rise in the load applied to the isogrid structure during buckling test;

- Isogrid structures can fail under local or global buckling, as a function of geometric parameters; the moisture content does not affect the failure mode;

- Irrespective of the rib thickness and moisture content taken into account, the maximum specific buckling load, decreases with the rib width, even though such effect is negligible as the undried configuration is considered. As the rib thickness increases, the maximum buckling load linearly growths until the rib thickness of $10 \mathrm{~mm}$ is reached; then, as the rib thickness further increases up to $15 \mathrm{~mm}$, the $P \max / \mathrm{w}$ value remains constant.

- The dried isogrid structures lead to an increase of both resistance and specific resistance;

- Moisture can be easily removed from thin isogrid structures;

- The more the moisture is removed, the more the increase in specific resistance is evident;

- The dried isogrid structures fail in a brittle manner while the undried ones present a ductile fracture;

- SEM images showed the differences on the fracture surfaces of dried and undried isogrids.

Removing moisture from CFRP realized using polyamide as matrix represents a key task to produce more performing composite components. Moreover, in order to avoid moisture adsorption during the use phase of components, surface coatings shall be considered, thus allowing the maintenance of the expected mechanical performances.

Future work will be focused on the comparison of FFF 3Dprinted composite structures with traditionally produced isogrid structures.

\section{Acknowledgment}

This research was founded by POR FESR Abruzzo 2014/2020, Linea di Azione 1.1.1 e 1.1.4, Avviso Pubblico per "Sostegno a progetti di Ricerca Industriale, Sviluppo Sperimentale e Innovazione delle PMI nelle aree di specializzazione S3" (CUP: C37H18000070007). The Grant of Excellence Departments, MIUR-Italy (ARTICOLO 1, COMMI 314-337 LEGGE 232/ 
2016) is also gratefully acknowledged. Authors acknowledge Roboze s.p.a. for the materials.

\section{Funding}

Open access funding provided by Università Politecnica delle Marche within the CRUI-CARE Agreement.

Open Access This article is licensed under a Creative Commons Attribution 4.0 International License, which permits use, sharing, adaptation, distribution and reproduction in any medium or format, as long as you give appropriate credit to the original author(s) and the source, provide a link to the Creative Commons licence, and indicate if changes were made. The images or other third party material in this article are included in the article's Creative Commons licence, unless indicated otherwise in a credit line to the material. If material is not included in the article's Creative Commons licence and your intended use is not permitted by statutory regulation or exceeds the permitted use, you will need to obtain permission directly from the copyright holder. To view a copy of this licence, visit http://creativecommons.org/licenses/by/4.0/.

\section{References}

1. I. Gibson, D.W. Rosen, B. Stucker, I. Gibson, D.W. Rosen and B. Stucker, Introduction and Basic Principles, Additive Manufacturing Technologies, Springer, Berlin, 2010, p 20-35

2. I. Gibson, D.W. Rosen, and B. Stucker, Additive Manufacturing Technologies: Rapid Prototyping to Direct Digital Manufacturing, Additive Manufacturing Technologies: Rapid Prototyping to Direct Digital Manufacturing, Springer, Berlin, 2010

3. A. Wojcieszynski, Special Issue Focus: Additive Manufacturing, $J$. Mater. Eng. Perform., 2019, 28(2), p 593. https://doi.org/10.1007/s11 665-019-3857-5

4. M.S. Hossain and H. Taheri, In Situ Process Monitoring for Additive Manufacturing Through Acoustic Techniques, J. Mater. Eng. Perform., 2020, 29(10), p 6249-6262. https://doi.org/10.1007/s11665-020-0512 5-w

5. V.K. Srivastava, P.K. Jain, P. Kumar, A. Pegoretti and C.R. Bowen, Smart Manufacturing Process of Carbon-Based Low-Dimensional Structures and Fiber-Reinforced Polymer Composites for Engineering Applications, J. Mater. Eng. Perform., 2020, 29, p 4162-4186

6. P.K. Penumakala, J. Santo and A. Thomas, A Critical Review on the Fused Deposition Modeling of Thermoplastic Polymer Composites, Compos. Part B Eng., 2020, 201, p 108336. https://doi.org/10.1016/j.c ompositesb.2020.108336

7. J. Jiang, J. Lou and G. Hu, Effect of Support on Printed Properties in Fused Deposition Modelling Processes, Virtual Phys. Prototyp., 2019, 14(4), p 308-315

8. P. Parandoush and D. Lin, A Review on Additive Manufacturing of Polymer-Fiber Composites, Compos. Struct., 2017, 182, p 36-53. h ttps://doi.org/10.1016/j.compstruct.2017.08.088

9. B. Brenken, E. Barocio, A. Favaloro, V. Kunc and R.B. Pipes, Fused Filament Fabrication of Fiber-Reinforced Polymers: A Review, Addit. Manuf., 2018, 21, p 1-16. https://doi.org/10.1016/j.addma.2018.01.002
10. F. Ning, W. Cong, J. Qiu, J. Wei and S. Wang, Additive Manufacturing of Carbon Fiber Reinforced Thermoplastic Composites Using Fused Deposition Modeling, Compos. Part B Eng., 2015, 80, p 369-378

11. C. Capela, J.M. Ferreira, J.M. Costa and N. Mendes, Mechanical Properties of Injection-Molded Glass Microsphere-Reinforced Polyamide, J. Mater. Eng. Perform., 2016, 25(10), p 4256-4265

12. E.V. de Toro, J.C. Sobrino, A.M. Martínez, V.M. Eguía and J.A. Pérez, Investigation of a Short Carbon Fibre-Reinforced Polyamide and Comparison of Two Manufacturing Processes: Fused Deposition Modelling (FDM) and Polymer Injection Moulding (PIM), Materials (Basel)., 2020, 13(3), p 672. https://doi.org/10.3390/ma13030672

13. X. Zhang, W. Fan and T. Liu, Fused Deposition Modeling 3D Printing of Polyamide-Based Composites and Its Applications, Compos. Commun., 2020, 21, p 100413. https://doi.org/10.1016/j.coco.2020.10 0413

14. A. Forcellese, M. Simoncini, A. Vita and V. Di Pompeo, 3D Printing and Testing of Composite Isogrid Structures, Int. J. Adv. Manuf. Technol., 2020, 109(7-8), p 1881-1893

15. A. Forcellese, V. di Pompeo, M. Simoncini and A. Vita, Manufacturing of Isogrid Composite Structures by 3D Printing, Procedia Manuf., 2020, 47, p 1096-1100. https://doi.org/10.1016/j.promfg.2020.04.123

16. A. Antony, Effect of RIB Orientation in Isogrid Structures: Aerospace Applications, Int J Sci Technol Eng, 2017, 3(11), p 319-327

17. L. Sorrentino, M. Marchetti, C. Bellini, A. Delfini and M. Albano, Design and Manufacturing of an Isogrid Structure in Composite Material: Numerical and Experimental Results, Compos. Struct., 2016, 143, p 189-201. https://doi.org/10.1016/j.compstruct.2016.02.043

18. D. Wang and M.M. Abdalla, Global and Local Buckling Analysis of Grid-Stiffened Composite Panels, Compos. Struct., 2015, 119, p 767776

19. E.S. Elumalai, G. Krishnaveni, R. Sarath Kumar, D. Dominic Xavier, G. Kavitha, S. Seralathan, V. Hariram and T. Micha Premkumar, Buckling Analysis of Stiffened Composite Curved Panels, Mater. Today Proc., 2020, 33, p 3604-3611

20. M. Li, C. Lai, Q. Zheng, B. Han, H. Wu and H. Fan, Design and Mechanical Properties of Hierarchical Isogrid Structures Validated by 3D Printing Technique, Mater. Des., 2019, 168, p 107664

21. I.V. Andrianov, A.L. Kalamkarov and D. Weichert, Buckling of Fibers in Fiber-Reinforced Composites, Compos. Part B Eng., 2012, 43(4), p 2058-2062

22. H.L. Tekinalp, V. Kunc, G.M. Velez-Garcia, C.E. Duty, L.J. Love, A.K. Naskar, C.A. Blue and S. Ozcan, Highly Oriented Carbon FiberPolymer Composites via Additive Manufacturing, Compos. Sci. Technol., 2014, 105, p 144-150

23. A. Hassan, N.M.M. Abd Rahman and R. Yahya, Moisture Absorption Effect on Thermal, Dynamic Mechanical and Mechanical Properties of Injection-Molded Short Glass-Fiber/Polyamide 6,6 Composites, Fibers Polym., 2012, 13(7), p 899-906

24. H.N. Dhakal, Z.Y. Zhang and M.O.W. Richardson, Effect of Water Absorption on the Mechanical Properties of Hemp Fibre Reinforced Unsaturated Polyester Composites, Compos. Sci. Technol., 2007, 67(78), p 1674-1683

25. D. Halápi, S.E. Kovács, Z. Bodnár, Á.B. Palotás, and L. Varga, Tensile Analysis of 3D Printer Filaments, MultiScience-XXXII, in microCAD International Multidisciplinary Scientific Conference (2018). https://d oi.org/10.26649/musci.2018.013

26. T. Letcher and M. Waytashek, Material Property Testing of 3D-Printed Specimen in PLA on an Entry-Level 3D Printer, Proc. ASME IMECE, 2014 https://doi.org/10.1115/IMECE2014-39379

Publisher's Note Springer Nature remains neutral with regard to jurisdictional claims in published maps and institutional affiliations. 